\title{
Evaluation of Family Planning Counselling in North Jordan
}

\section{تقييم خدمات تقديم مشورة تنظيم الأسرة في شمال الأردن}

$$
\text { عبدالحكيم محمود عكور، رامي عبداله سعادة، منى زقول }
$$

ABSTRACT: Objectives: Counselling plays a key role in enhancing reproductive services, providing contraceptionrelated information and supporting long-term family planning for women of childbearing age. This study aimed to evaluate family planning counselling sessions in selected governmental and private clinics in northern Jordan. Methods: This cross-sectional study was conducted between January and June 2016 in Irbid, Jordan. A total of 200 women attending two private clinics affiliated with the Jordanian Association for Family Planning and Protection (JAFPP) and six governmental clinics were invited to participate in the study. Counselling sessions were attended by an independent observer and evaluated with regards to their compliance with the standard Greet, Ask, Tell, Help, Explain, Return (GATHER) framework. Results: A total of 198 women participated in the study (response rate: $99.0 \%)$, including 80 women (40.4\%) from JAFPP clinics and 118 (59.6\%) from governmental clinics. In total, $42.9 \%$ of the counselling sessions were deemed adequate, with providers applying $80 \%$ or more of the GATHER framework, while $26.8 \%$ of the sessions were deemed semi-adequate and $30.3 \%$ were considered inadequate. Counselling services provided in the governmental clinics were significantly less adequate than those provided in JAFPP clinics $(P<0.001)$. Conclusion: The quality of counselling services in governmental family planning centres in Jordan needs to be improved to ensure that women receive the highest possible level of care. Healthcare policymakers should therefore focus on developing and supporting effective family planning counselling services in northern Jordan.

Keywords: Family Planning Services; Counseling; Health Services Evaluation; Community Health Services; Reproductive Health; Jordan.

الملخص: الهذف: تؤدي المشورة دورا رئيسيا في تعزيز الخدمات الإنجابية، وتوفير المعلومات المتعلقة بمنع الحمل، ودعم تنظيم

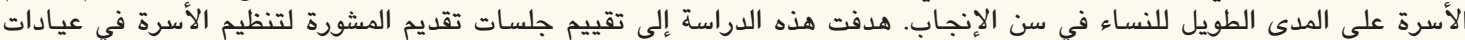

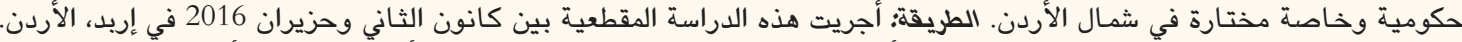

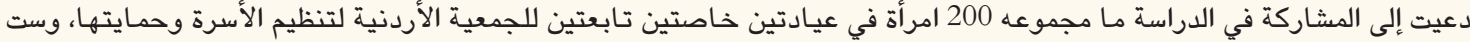

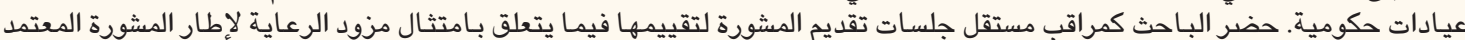

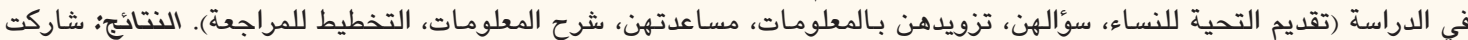

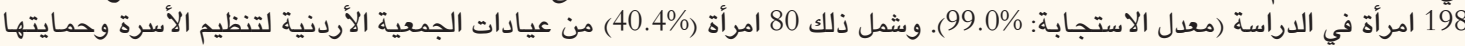

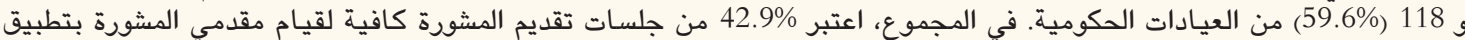

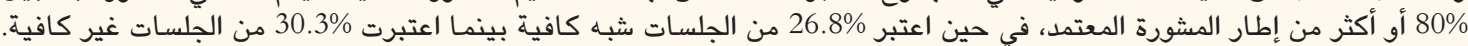

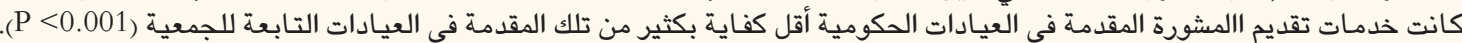

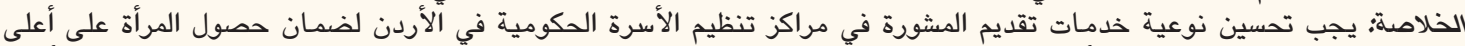

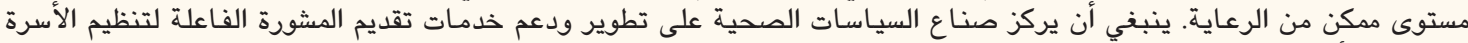
في شمال الأردن.

الكلمات المفتاحية: خدمات تنظيم الأسرة؛ تقديم المشورة؛ تقييم الخدمات الصحية؛ خدمات الصحة الهجمعية؛ الصحة الإنجابية؛ الأردن.

\section{Advances in KNOWLedge}

To the best of the authors' knowledge, this study is the first to evaluate family planning counselling sessions in northern Jordan in terms of their adherence to the standard Greet, Ask, Tell, Help, Explain, Return (GATHER) framework.

This study provides information for healthcare policy-makers in Jordan regarding differences in the adequacy of family planning counselling in Jordan at private and governmental institutions.

\section{Application to Patient Care}

The results of the current study demonstrated that family planning counselling in governmental centres in Jordan was substandard and needs to be improved. 
$\mathrm{F}$ AMILY PLANNING COUNSELLING ENHANCES reproductive outcomes by supporting a woman's decision to use appropriate contraceptive methods in the manner that best fits her needs. ${ }^{1-3}$ During counselling sessions, healthcare providers can provide patients with expert clinical advice regarding contraceptive choices. However, inadequate communication between service providers and patients may impact the disclosure or understanding of salient information concerning the appropriate use and sideeffects of various contraceptives, which may in turn lead to contraceptive discontinuation. ${ }^{4,5}$ Evidence indicates that structured counselling both protects women's rights to an informed and voluntary decision regarding their reproductive choices and improves the use of modern contraception methods. ${ }^{5-12}$

Ideally, counselling sessions should be acceptable to the patient, provide high-quality information and offer enough time and motivation to apply any recommendations. ${ }^{13}$ According to the World Health Organization (WHO), a successful counsellor should understand women's beliefs, needs and concerns and be respectful, honest, highly competent and an effective communicator. ${ }^{14,15}$ In Jordan, family planning services are provided by the Ministry of Health $(\mathrm{MOH})$ free of charge for those with governmental insurance and at a minimum charge for those without. In the private medical sector, such services are either partially or totally funded by insurance providers. Although the fertility rate in recent years has remained essentially unchanged, with a decline from 3.5 births per woman in 2012 to 3.4 births per woman in 2015, one in three pregnancies is unintentional. 11,16

In 2012, 61.2\% of married Jordanian women were reported to be using some method of family planning, with $42.3 \%$ using modern methods and $18.9 \%$ using traditional methods. ${ }^{4}$ In total, $44.1 \%$ of women who used modern contraceptives obtained them from a governmental source while $55.6 \%$ received them from private institutions, including pharmacies, the Jordan Association of Family Planning and Protection (JAFPP), the United Nations Refugee Welfare Agency and private doctors. However, $11.7 \%$ had an unmet need for family planning-whether it was to postpone their next birth or to avoid pregnancy altogether-but were not using any form of contraception. ${ }^{4}$ Moreover, a high rate of contraceptive discontinuation within 12 months of use (47.8\%) was reported, with only $24.2 \%$ subsequently switching to another method. The main reasons for contraceptive discontinuation included contraceptive failure $(8.6 \%)$, the desire for a more effective contraceptive (10.0\%), undesirable side-effects (5.2\%) or wanting to become pregnant (9.9\%). ${ }^{4}$
Another national study in Jordan has indicated that family planning services are often influenced by the personal beliefs of the providers; for example, most providers emphasised the importance of a large family and recommended short-term contraceptive methods for women with fewer children, refusing to suggest semipermanent approaches like an intrauterine device. ${ }^{5}$ Religious and social beliefs also influenced family planning recommendations, with some providers expressing preference for a male child. ${ }^{5}$ According to the 2015-2019 strategic plan of the $\mathrm{MOH}$, the strengthening of reproductive health services is a top priority. ${ }^{16}$

However, despite the existence of $\mathrm{MOH}$ guidelines, relatively little is known regarding the actual magnitude or quality of family planning counselling sessions in Jordan. One study indicated a 20\% increase in patient satisfaction with family planning services with each additional counselling protocol step. ${ }^{5}$ Another study previously investigated the effect of involving men in counselling; however, the content of the sessions was not evaluated. ${ }^{11}$ Finally, various other studies have analysed general family planning services rather than focusing specifically on counselling. ${ }^{17-21}$ The present study therefore aimed to evaluate family planning counselling sessions at governmental and private clinics in northern Jordan in terms of their adherence to the Greet, Ask, Tell, Help, Explain, Return (GATHER) framework. ${ }^{22}$

\section{Methods}

This descriptive cross-sectional study was conducted in Irbid, Jordan, between January and June 2016. A total of 200 women attending one of eight selected family planning clinics during the study period were invited to participate in the study. Of the eight clinics, six were run by the Jordanian $\mathrm{MOH}$ and two by the JAFPP, which is the largest non-governmental provider of family planning services in Jordan, serving roughly $20 \%$ of the population with 19 clinics nationwide. ${ }^{23}$ The target population included all women who visited the selected clinics during the data collection period, including those attending during their postpartum period, first-time users and those seeking contraceptive advice. The sample size was determined based on the following formula: ${ }^{24}$

$$
\mathrm{N}=\frac{\mathrm{Z}_{\alpha / 2} \mathrm{p}^{*} \mathrm{q}}{\mathrm{d}^{2}}
$$

where $\mathrm{N}$ is the sample size, $\mathrm{Z} \alpha$ is 1.96 (using a corresponding value of $\mathrm{Z}$ from standard tables), $\mathrm{p}$ is the prevalence of incompetent family planning 
Table 1: Assessment checklist for the evaluation of counselling sessions according to the Greet, Ask, Tell, Help, Explain, Return (GATHER) framework ${ }^{22}$

\begin{tabular}{|c|c|}
\hline Item & Assessment \\
\hline Greet & $\begin{array}{l}\text { Greets the client in a friendly and respectful } \\
\text { manner? }\end{array}$ \\
\hline \multirow[t]{2}{*}{ Ask } & Asks about the client's needs and concerns? \\
\hline & Asks about the client's reproductive goals? \\
\hline \multirow[t]{9}{*}{ Tell } & $\begin{array}{l}\text { Informs the client of all contraceptive } \\
\text { methods available? }\end{array}$ \\
\hline & Asks which method interests client? \\
\hline & $\begin{array}{l}\text { Asks what the client already knows about } \\
\text { the method? }\end{array}$ \\
\hline & $\begin{array}{l}\text { Corrects myths/rumours/incorrect } \\
\text { information? }\end{array}$ \\
\hline & Describes the effectiveness of the method? \\
\hline & Uses audio/visual aids during counselling? \\
\hline & Describes the benefits and risks? \\
\hline & Describes potential side-effects? \\
\hline & Answers the client's questions clearly? \\
\hline \multirow[t]{2}{*}{ Help } & Asks if anything is not understood? \\
\hline & Asks "what method do you want"? \\
\hline \multirow[t]{5}{*}{ Explain } & $\begin{array}{l}\text { Clearly explains instructions on successfully } \\
\text { using the method? }\end{array}$ \\
\hline & Asks the client to repeat instructions? \\
\hline & Reminds the client of potential side-effects? \\
\hline & $\begin{array}{l}\text { Reminds the client of dangerous signs/ } \\
\text { symptoms? }\end{array}$ \\
\hline & Explains what to do if problems occur? \\
\hline Return & Plans a return visit for the client? \\
\hline
\end{tabular}

counselling (15\% as determined according to a pilot study), q is the difference between 100 and p (100 - 15 $=85 \%)$ and $\mathrm{d}$ is the precision of the estimate indicating an absolute error of 0.05 . As such, the required sample size was calculated to be 196 .

In JAFPP clinics, family planning services were provided during fixed-time appointments. Women had to register and have their blood pressure measured before each counselling session, which was then undertaken by two social workers in a separate room designed specifically for that purpose. In contrast, family planning services at governmental facilities were provided on a 'first-come, first-served' basis, with registration, vital signs measurements and counselling sessions all performed in a single room with multiple personnel present, including nurses, midwifes and nurse assistants; however, midwives were the sole care givers to provide counselling services. Unfortunately, as each clinic had a different daily schedule for various services and the time duration for the counselling sessions was irregular, the process of participant recruitment and data collection was not simple. In view of these factors, as well as the limited time period of the study, coordination with the facilities and the data collection process was carried out by a single person.

Accordingly, the observation and evaluation of counselling sessions was carried out by a single anonymous observer unrelated to the researchers. The observer remained present in the counselling room from 8 AM to 1 PM during the entirety of each session. For the evaluation, a modified 20 -item checklist was derived using the components of the original GATHER framework [Table 1]. ${ }^{22}$ This checklist was pretested prior to data collection in a pilot study of 15 women not subsequently included in the main study; the findings confirmed that each of the items was appropriate and understandable. Subjective items were avoided and none of the items were deemed to present difficulties during evaluation or considered potentially controversial when reviewed by a panel of researchers. During each counselling session, the observer witnessed the counselling process and awarded one mark for each checklist item; the marks were subsequently added up for a total score of 20 points. Scores of $\leq 9(\leq 45 \%)$ were classified as inadequate, while scores of 10-15 (50-75\%) and $\geq 16$ ( $\geq 80 \%$ ) were classified as semi-adequate and adequate, respectively. In addition, a stopwatch was used to time the duration of counselling sessions from the moment the patient stepped into the room until the provider finished the session. After each session, the participants were requested to complete a sociodemographic questionnaire to record their age, education level, employment status, age at marriage, number of children and monthly income.

Analysis of the data was performed using the Statistical Package for the Social Sciences (SPSS), Version 22.0 (IBM Corp., Armonk, New York, USA). The main outcome variable of the study was the evaluation score of the counselling performed by healthcare providers. Results were presented using descriptive statistics, including frequencies and means. The relationship between facility type and both the adequacy and duration of the counselling session was assessed as well as between the adequacy of the counselling process and the duration of the session. A $P$ value of 0.050 was considered statistically significant. 
Table 2: Characteristics of women attending selected family planning clinics in Irbid, Jordan $(\mathrm{N}=198)$

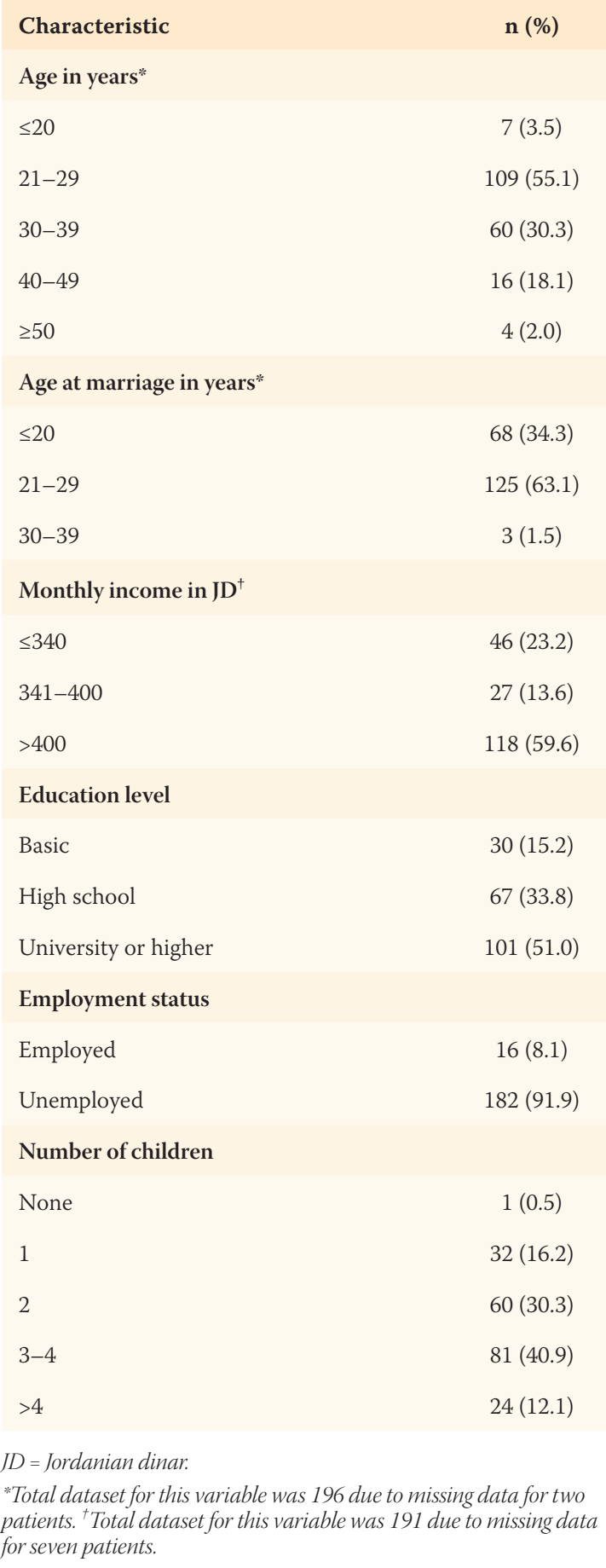

This study was approved by the Institutional Review Board of the Jordan University of Science \& Technology (\#139/2015) as well as relevant authorities at the $\mathrm{MOH}$ and JAFPP. Verbal consent was obtained from each of the counselling providers before the monitoring of their counselling sessions. Patients provided written informed consent prior to their participation in the study and were assured of the voluntary nature of their participation and the confidentiality of any data collected.
Table 3: Evaluation of family planning counselling sessions at selected clinics in Irbid, Jordan $(\mathrm{N}=198)$

\begin{tabular}{|c|c|c|c|}
\hline & \multicolumn{2}{|c|}{ n (\%) } \\
\hline \multicolumn{2}{|c|}{ Assessment" } & \multirow{2}{*}{$\begin{array}{c}\begin{array}{c}\text { MOH } \\
\text { clinics } \\
(\mathbf{n}=118)\end{array} \\
118 \\
(100.0)\end{array}$} & \multirow{2}{*}{$\begin{array}{c}\text { JAFPP } \\
\text { clinics } \\
(\mathbf{n}=\mathbf{8 0}) \\
\\
80 \\
(100.0)\end{array}$} \\
\hline Greet & $\begin{array}{l}\text { Greets the client in a } \\
\text { friendly and respectful } \\
\text { manner? }\end{array}$ & & \\
\hline \multirow[t]{2}{*}{ Ask } & $\begin{array}{l}\text { Asks about the client's } \\
\text { needs and concerns? }\end{array}$ & $\begin{array}{c}118 \\
(100.0)\end{array}$ & \multirow{2}{*}{$\begin{array}{c}80 \\
(100.0) \\
80 \\
(100.0)\end{array}$} \\
\hline & $\begin{array}{l}\text { Asks about the client's } \\
\text { reproductive goals? }\end{array}$ & $\begin{array}{c}118 \\
(100.0)\end{array}$ & \\
\hline \multirow[t]{9}{*}{ Tell } & $\begin{array}{l}\text { Informs the client } \\
\text { of all contraceptive } \\
\text { methods available? }\end{array}$ & $\begin{array}{c}38 \\
(32.2)\end{array}$ & $\begin{array}{c}25 \\
(31.3)\end{array}$ \\
\hline & $\begin{array}{l}\text { Asks which method } \\
\text { interests the client? }\end{array}$ & $\begin{array}{c}115 \\
(97.5)\end{array}$ & $\begin{array}{c}80 \\
(100.0)\end{array}$ \\
\hline & $\begin{array}{l}\text { Asks what the client } \\
\text { already knows about } \\
\text { the method? }\end{array}$ & $\begin{array}{c}1 \\
(0.8)\end{array}$ & $\begin{array}{c}11 \\
(13.8)\end{array}$ \\
\hline & $\begin{array}{l}\text { Corrects myths/ } \\
\text { rumours/incorrect } \\
\text { information? }\end{array}$ & $\begin{array}{c}36 \\
(30.5)\end{array}$ & $\begin{array}{c}80 \\
(100.0)\end{array}$ \\
\hline & $\begin{array}{l}\text { Describes the } \\
\text { effectiveness of the } \\
\text { method? }\end{array}$ & $\begin{array}{c}35 \\
(29.7)\end{array}$ & $\begin{array}{c}79 \\
(98.8)\end{array}$ \\
\hline & $\begin{array}{l}\text { Uses audio/visual aids } \\
\text { during counselling? }\end{array}$ & $\begin{array}{c}2 \\
(1.7)\end{array}$ & $\begin{array}{c}78 \\
(97.5)\end{array}$ \\
\hline & $\begin{array}{l}\text { Describes the benefits } \\
\text { and risks? }\end{array}$ & $\begin{array}{c}45 \\
(38.1)\end{array}$ & $\begin{array}{c}80 \\
(100.0)\end{array}$ \\
\hline & $\begin{array}{l}\text { Describes the } \\
\text { potential side-effects? }\end{array}$ & $\begin{array}{c}52 \\
(44.1)\end{array}$ & $\begin{array}{c}80 \\
(100.0)\end{array}$ \\
\hline & $\begin{array}{l}\text { Answers the client's } \\
\text { questions clearly? }\end{array}$ & $\begin{array}{c}69 \\
(58.5)\end{array}$ & $\begin{array}{c}80 \\
(100.0)\end{array}$ \\
\hline \multirow[t]{2}{*}{ Help } & $\begin{array}{l}\text { Asks if anything is not } \\
\text { understood? }\end{array}$ & $\begin{array}{c}3 \\
(2.5)\end{array}$ & $\begin{array}{c}80 \\
(100.0)\end{array}$ \\
\hline & $\begin{array}{l}\text { Asks "what method do } \\
\text { you want"? }\end{array}$ & $\begin{array}{c}118 \\
(100.0)\end{array}$ & $\begin{array}{c}80 \\
(100.0)\end{array}$ \\
\hline \multirow[t]{5}{*}{ Explain } & $\begin{array}{l}\text { Clearly explains } \\
\text { instructions on } \\
\text { successfully using the } \\
\text { method? }\end{array}$ & $\begin{array}{c}42 \\
(35.6)\end{array}$ & $\begin{array}{c}80 \\
(100.0)\end{array}$ \\
\hline & $\begin{array}{l}\text { Asks the client } \\
\text { to repeat back } \\
\text { instructions? }\end{array}$ & $\begin{array}{c}0 \\
(0.0)\end{array}$ & $0(0.0)$ \\
\hline & $\begin{array}{l}\text { Reminds the client } \\
\text { of the potential side- } \\
\text { effects? }\end{array}$ & $\begin{array}{c}51 \\
(43.2)\end{array}$ & $\begin{array}{c}80 \\
(100.0)\end{array}$ \\
\hline & $\begin{array}{l}\text { Reminds the client } \\
\text { of dangerous signs/ } \\
\text { symptoms? }\end{array}$ & $\begin{array}{c}36 \\
(30.5)\end{array}$ & $\begin{array}{c}80 \\
(100.0)\end{array}$ \\
\hline & $\begin{array}{l}\text { Explains what to do if } \\
\text { problems occur? }\end{array}$ & $\begin{array}{c}60 \\
(50.8)\end{array}$ & $\begin{array}{c}80 \\
(100.0)\end{array}$ \\
\hline Return & $\begin{array}{l}\text { Plans a return visit for } \\
\text { the client? }\end{array}$ & $\begin{array}{l}102 \\
(86.4)\end{array}$ & $\begin{array}{c}78 \\
(97.5)\end{array}$ \\
\hline
\end{tabular}

$M O H=$ Ministry of Health $;$ IAFPP $=$ Jordan Association of Family Planning and Protection.

"As per the Greet, Ask, Tell, Help, Explain, Return (GATHER) framework. ${ }^{22}$ 
Table 4: Relationship between facility type and evaluation outcomes and duration of family planning counselling sessions at selected clinics in Irbid, Jordan $(\mathrm{N}=198)$

\begin{tabular}{|c|c|c|}
\hline & n (\%) & \\
\hline $\begin{array}{c}\mathrm{MOH} \\
\text { clinics } \\
(\mathrm{n}=118)\end{array}$ & $\begin{array}{l}\text { JAFPP } \\
\text { clinics } \\
(\mathrm{n}=80)\end{array}$ & Total \\
\hline
\end{tabular}

Evaluation outcome*

$\begin{array}{lcccl}\text { Adequate } & 5 & 80 & 85 & \\ & (4.2) & (100.0) & (42.9) & \\ \text { Semi-adequate } & 53 & 0 & 53 & \\ & (44.9) & (0.0) & (26.8) & <0.001 \\ \text { Inadequate } & 60 & 0 & 60 & \\ & (50.8) & (0.0) & (30.3) & \end{array}$

Session duration in minutes

$\begin{array}{lcccc}\leq 5 & 58 & 2 & 60 & \\ & (49.2) & (2.5) & (30.3) & \\ 6-10 & 46 & 27 & 73 & \\ & (39.0) & (33.8) & (36.9) & \\ 11-15 & 12 & 44 & 56 & \\ & (10.2) & (55.0) & (28.3) & <0.001 \\ 16-20 & 0 & 6 & 6 & \\ & (0.0) & (7.5) & (3.0) & \\ >20 & 2 & 1 & 3 & \\ & (1.7) & (1.3) & (1.5) & \end{array}$

$M O H=$ Ministry of Health $;$ IAFPP $=$ Jordan Association of Family Planning and Protection.

"As per the Greet, Ask, Tell, Help, Explain, Return (GATHER) framework. ${ }^{22}$

\section{Results}

A total of 198 women participated in the study (response rate: $99.0 \%)$, including 80 women (40.4\%) from JAFPP clinics and 118 (59.6\%) from MOH clinics. The mean age was 22 years (range: $17-56$ years old) and $85.4 \%$ were between 21-39 years old. The age of the women at their marriage ranged between $15-35$ years old. In total, $84.8 \%$ were educated to high school level or higher and $73.2 \%$ had monthly incomes of $>340$ Jordanian dinars (USD > \$480). The mean number of children per woman was three, with $53.0 \%$ of the participants having three or more children [Table 2].
Table 3 shows the evaluation of observed counselling sessions according to the GATHER framework. ${ }^{22}$ Both types of clinics consistently and adequately performed the first two steps of the GATHER framework (Greet and Ask). Moreover, in the private JAFPP clinics, all of the other steps of the GATHER framework (Tell, Help, Explain and Return) were deemed to be adequate; however, in the governmental clinics, these steps were assessed as either semiadequate or inadequate. The mean evaluation score was 12.88 (range: $5-19$ ).

Of all the counselling sessions, 30.3\% were considered inadequate, $26.8 \%$ were semi-adequate, and $42.9 \%$ were adequate. However, $100.0 \%$ of JAFPP clinic sessions were deemed adequate in comparison to only $4.2 \%$ of governmental clinic sessions. Moreover, while $88.8 \%$ of counselling sessions in JAFPP clinics lasted 6-15 minutes, only $49.2 \%$ of counselling sessions in governmental clinics lasted for the same amount of time. The relationships between facility type and evaluation outcome $(P<0.001)$ and counselling duration $(P<0.001)$ were highly significant [Table 4]. Adequate counselling sessions lasted between 6-20 minutes in $95.3 \%$ of cases, while semi-adequate and inadequate sessions lasted between $2-10$ minutes in $81.2 \%$ and $96.6 \%$ of cases, respectively, with a significant relationship between evaluation outcome and counselling duration $(P<0.001)$ [Table 5].

\section{Discussion}

The provision of high-quality family planning services encourages acceptance of contraceptive use..$^{25}$ Moreover, evidence from both developed and developing countries shows that high-quality care assists in reducing rates of contraceptive discontinuation and unintended fertility. ${ }^{25,26}$ To the best of the author's knowledge, the current study is the first in Jordan to evaluate family planning counselling sessions according to the GATHER framework. ${ }^{22}$ In the current

Table 5: Relationship between evaluation outcomes* and duration of family planning counselling sessions at selected clinics in Irbid, Jordan $(\mathrm{N}=198)$

\begin{tabular}{|c|c|c|c|c|c|}
\hline \multirow{2}{*}{$\begin{array}{l}\text { Session duration } \\
\text { in minutes }\end{array}$} & \multicolumn{4}{|c|}{ n (\%) } & \multirow[t]{2}{*}{$P$ value } \\
\hline & $\begin{array}{l}\text { Adequate sessions } \\
\qquad(\mathrm{n}=85)\end{array}$ & $\begin{array}{l}\text { Semi- adequate sessions } \\
\qquad(\mathbf{n}=53)\end{array}$ & $\begin{array}{l}\text { Inadequate sessions } \\
\qquad(\mathrm{n}=60)\end{array}$ & Total & \\
\hline$\leq 5$ & $3(3.5)$ & $11(20.8)$ & $46(76.7)$ & $60(30.3)$ & \\
\hline $6-10$ & 29 (34.1) & $32(60.4)$ & $12(20.0)$ & $73(36.9)$ & \\
\hline $11-15$ & $46(54.1)$ & $9(17.0)$ & $1(1.7)$ & $56(28.3)$ & $<0.001$ \\
\hline $16-20$ & $6(7.1)$ & $0(0.0)$ & $0(0.0)$ & $6(3.0)$ & \\
\hline$>20$ & $1(1.2)$ & $1(1.9)$ & $1(1.7)$ & $3(1.5)$ & \\
\hline
\end{tabular}

*As per an assessment checklist based on the Greet, Ask, Tell, Help, Explain, Return (GATHER) framework. ${ }^{22}$ 
study, the overall rate of adequate counselling was acceptable when considering all counselling sessions together, regardless of facility type; however, the situation was markedly different when considering the results for $\mathrm{MOH}$ clinics alone. Other countries have reported better results pertaining to the evaluation of family planning services in general, and for counselling in particular. ${ }^{27-29}$

The findings of the current study suggest that social workers working in JAFPP clinics more consistently employed the GATHER framework while counselling in contrast to $\mathrm{MOH}$ midwives at governmental clinics. ${ }^{22}$ Moreover, certain aspects of the GATHER framework-including the use of audiovisual aids and asking what the client already knew about contraceptive methods and whether anything was not understood-were applied more consistently in JAFPP clinics compared to $\mathrm{MOH}$ clinics. ${ }^{22}$ Although outside the scope of this study, it is possible that differences in the standards of services available at each type of facility may be responsible for these results. Previous research has indicated that improved conditions in family health facilities and the application of appropriate counselling protocols lead to improved family planning services. ${ }^{26}$ In $\mathrm{MOH}$ clinics, women rarely received counselling services as they were seen on a 'walk-in' basis, with family planning services usually restricted to the provision of contraceptives. This may be partially due to the extremely large number of women seen by $\mathrm{MOH}$ clinics which far surpass those seen by other family planning providers in Jordan.

Furthermore, healthcare providers at $\mathrm{MOH}$ clinics had no incentives and few expectations placed on them with regards to family planning services and thus little motivation to offer high-quality counselling sessions. ${ }^{2,27}$ In addition, the lack of separate rooms for counselling sessions and the time demands on $\mathrm{MOH}$ employees would not facilitate the provision of counselling services. To some extent, the lack of professional training on counselling protocols and the 'walk-in'-based system might explain the low level of counselling competency noted at $\mathrm{MOH}$ clinics in the current study. In contrast, counselling in JAFPP clinics was performed by trained social workers in specifically designed rooms. Such conditions offer a client-centred and friendly atmosphere for family planning services. ${ }^{17,18,27,28}$ Moreover, the time allocation for each patient was determined by an appointmentbased system which may have helped to assure the quality of counselling. In 2009, the Jordanian Higher Population Council recommended restructuring $\mathrm{MOH}$ protocols for the provision, evaluation and monitoring of family planning counselling services in order to reduce contraceptive failure, incorrect use and discontinuation rates. ${ }^{13}$ Furthermore, compulsory training courses were recommended for all $\mathrm{MOH}$ healthcare providers in order to facilitate more effective counselling sessions. ${ }^{13}$ Training healthcare providers to be counselling specialists might also contribute to improved client services. ${ }^{29}$ Previous studies have ascertained that specialised training increases providers' knowledge of contraceptives and their willingness to prescribe appropriate methods. ${ }^{2,26,27,29}$ Continuous evidence-based training is therefore a promising approach for enhancing counselling services at $\mathrm{MOH}$ clinics in Jordan.

Counselling services can be provided by a variety of healthcare providers, including midwifes, nurses and doctors. ${ }^{2,27,29}$ Although the current study did not address the skills or qualifications of the various counselling providers, the results seem to indicate that midwives with specialised medical education and training in $\mathrm{MOH}$-affiliated clinics could not compete with social workers without health-related training or medical education in private clinics. An essential component in the provision of high-quality counselling is effective and efficient communication skills. It is possible that such skills could be lacking among the midwives involved in the current study. Often, women or couples seeking family planning counselling services are from diverse backgrounds and can challenge the competencies of counselling providers to respect their patients' experiences, opinions and thoughts. ${ }^{5}$ Competent counselling sessions also require the allocation of adequate time to best serve the patient. In the current study, the mean duration of counselling sessions was relatively similar to other research (8.68 minutes versus 5-15 minutes). ${ }^{5}$ In the present study, longer counselling sessions had better evaluation outcomes while shorter counselling sessions had lower scores (i.e. $76.7 \%$ of inadequate sessions took $\leq 5$ minutes).

The findings of this study have various implications for research and healthcare practice. First, they contribute to the existing literature, since there is a dearth of studies evaluating family planning counselling sessions in Jordan. Second, they revealed several potential areas of related research that can be conducted in Jordan and the wider Middle Eastern region. Finally, they may assist policy-makers designing large-scale family planning programmes at the national level. Nevertheless, this study was subject to certain limitations. It is possible that the researchers overlooked factors which contributed to the different results observed between the two types of clinics evaluated. Additionally, since the data collector had more time to contact and recruit eligible women in 
governmental facilities, more women were recruited from $\mathrm{MOH}$ clinics than from JAFPP ones. As such, the total sample of women included in the study was small and not randomly selected, thus limiting generalisation of the results. In addition, a follow-up study was not carried out to examine the impact of counselling on contraceptive choice or discontinuation rates.

\section{Conclusion}

The current study assessed the provision of family planning counselling services in selected clinics in northern Jordan. Overall, the results showed that counselling sessions in both $\mathrm{MOH}$ and JAFPP facilities succeeded in following the first two steps of the GATHER framework in terms of welcoming patients and asking about their contraceptive choices. Nonetheless, counselling services at governmental clinics were otherwise deficient, particularly with regards to other interactions required by the GATHER framework. Hopefully, these results can be utilised by healthcare policy-makers to further develop family planning services in Jordan.

\section{CONFLICT OF INTEREST}

The authors declare no conflicts of interest.

\section{FUNDING}

No funding was received for this study.

\section{References}

1. Halpern V, Lopez LM, Grimes DA, Stockton LL, Gallo MF. Strategies to improve adherence and acceptability of hormonal methods of contraception. Cochrane Database Syst Rev 2013; 10:CD004317. doi: 10.1002/14651858.CD004317.pub4.

2. Saka MJ, Yahaya LA, Saka AO. Counseling and client providerinteractions as related to family planning services in Nigeria. J Educ Pract 2012; 3:16-24.

3. Malawi Ministry of Health. Preservice education family planning reference guide. From: www.intrahealth.org/sites/ihweb/files/ files/media/preservice-education-family-planning-referenceguide/MPsFPRG_final_web-opt.pdf Accessed: Sep 2017.

4. Department of Statistics. Jordan population and family health survey 2012. From: https://dhsprogram.com/pubs/pdf/FR282/ FR282.pdf Accessed: Sep 2017.

5. Kamhawi S, Underwood C, Murad H, Jabre B. Client-centered counseling improves client satisfaction with family planning visits: Evidence from Irbid, Jordan. Glob Health Sci Pract 2013; 1:180-92. doi: 10.9745/GHSP-D-12-00051.

6. Bruce J. Fundamental elements of the quality of care: A simple framework. Stud Fam Plann 1990; 21:61-91.

7. Khader YS, El-Qaderi S, Khader AM. Intrauterine contraceptive device discontinuation among Jordanian women: Rate, causes and determinants. J Fam Plann Reprod Health Care 2006; 32:161-4. doi: 10.1783/147118906777888279.
8. RamaRao S, Mohanam R. The quality of family planning programs: Concepts, measurements, interventions, and effects. Stud Fam Plann 2003; 34:227-48. doi: 10.1111/j.1728-4465. 2003.00227.x.

9. Moos MK, Dunlop AL, Jack BW, Nelson L, Coonrod DV, Long $\mathrm{R}$, et al. Healthier women, healthier reproductive outcomes: Recommendations for the routine care of all women of reproductive age. Am J Obstet Gynecol 2008; 199:S280-9. doi: 10.1016/j.ajog.2008.08.060.

10. Elsinga J, de Jong-Potjer LC, van der Pal-de Bruin KM, le Cessie S, Assendelft WJ, Buitendijk SE. The effect of preconception counselling on lifestyle and other behaviour before and during pregnancy. Womens Health Issues 2008; 18:S117-25. doi: 10.1016/j.whi.2008.09.003.

11. El-Khoury M, Thornton R, Chatterji M, Kamhawi S, Sloane P, Halassa M. Counseling women and couples on family planning: A randomized study in Jordan. Stud Fam Plann 2016; 47:222-38. doi: $10.1111 /$ sifp.69.

12. Lemani C, Tang JH, Kopp D, Phiri B, Kumvula C, Chikosi L, et al. Contraceptive uptake after training community health workers in couples counseling: A cluster randomized trial. PLoS One 2017; 12:e0175879. doi: 10.1371/journal.pone.0175879.

13. United States Agency for International Development. Reducing discontinuation of contraceptive use and unmet need for family planning: Policy options. From: www.healthpolicyinitiative. com/Publications/Documents/1488_1_Jordan_Unmet_Need_ Brief_Jan_2011.pdf Accessed: Sep 2017.

14. World Health Organization. Family planning: A global handbook for providers. From: www.ippf.org/sites/default/ files/family_planning_a_global_handbook_for_providers.pdf Accessed: Sep 2017.

15. Kim YM, Davila C, Tellez C, Kols A. Evaluation of the World Health Organization's family planning decision-making tool: Improving health communication in Nicaragua. Patient Educ Couns 2007; 66:235-42. doi: 10.1016/j.pec.2006.12.007.

16. Jordan High Health Council. The national strategy for health sector in Jordan: 2015-2019. From: www.hhc.gov.jo/ uploadedimages/The $\% 20$ National\%20Strategy\%20for $\% 20$ Health\%20Sector\%20in\%20Jordan\%202015-2019.pdf Accessed: Sep 2017.

17. United States Agency for International Development. Impact of changing contraceptive method mix on Jordan's total fertility rate. From: pdf.usaid.gov/pdf_docs/Pnadx849.pdf Accessed: Sep 2017.

18. Bitar N, Shahrouri M. Ministry of Health service providers knowledge on how to manage IUDs \& OCs side effects. From: bluerayjo.com/hpc/en/node/11870 Accessed: Sep 2017.

19. Abdelnour SF. MOH physicians' KAP study on hormonal methods and female sterilization. From: pdf.usaid.gov/pdf docs/Pnadn121.pdf Accessed: Sep 2017.

20. Mahadeen AI, Khalil AO, Hamdan-Mansour AM, Sato T, Imoto A. Knowledge, attitudes and practices towards family planning among women in the rural southern region of Jordan. East Mediterr Health J 2012; 18:567-72.

21. Mawajdeh S. Demographic profile and predictors of unmet need for family planning among Jordanian women. J Fam Plann Reprod Health Care 2007; 33:53-6. doi: 10.1783/ 147118907779399819.

22. Rinehart W, Rudy S, Drennan M. GATHER guide to counseling. Popul Rep J 1998; 48:1-31.

23. United States Agency for International Development. Jordan Association for Family Planning and Protection: Needs assessment. From: www.shopsplusproject.org/sites/default/ files/resources/6\%20Needs\%20Assessment $\% 2$ C\%20Jordan $\% 20$ Association $\% 20$ for $\% 20$ Family\%20 Planning $\% 20$ and $\% 20$ Protection\%2C\%20PSP-Jordan\%2C\%20Aug.\%202008.pdf Accessed: Sep 2017. 
24. Macinko J, Almeida C, de Sá PK. A rapid assessment methodology for the evaluation of primary care organization and performance in Brazil. Health Policy Plan 2007; 22:167-77. doi: 10.1093/heapol/czm008.

25. Shahidzadeh-Mahani A, Omidvari S, Baradaran HR, Azin SA Factors affecting quality of care in family planning clinics: A study from Iran. Int J Qual Health Care 2008; 20:284-90. doi: 10.1093/intqhe/mzn016.

26. Rawal N, Das G, Kishen M. Assessment of contraceptive services in a maternity unit of a district general hospital in the UK. J Obstet Gynaecol 2005; 25:179-81. doi: 10.1080/ 01443610500051478
27. Stanback J, Griffey S, Lynam P, Ruto C, Cummings S. Improving adherence to family planning guidelines in Kenya: An experiment. Int J Qual Health Care 2007; 19:68-73. doi: 10. 1093/intqhc/mzl072.

28. Eryilmaz G. The evaluation of family planning services given in Erzurum mother-child health and family planning centerin Eastern Turkey. Eur J Contracept Reprod Health Care 2006; 11:146-50. doi: 10.1080/13625180500520141.

29. Malnory ME, Johnson TS. The reproductive life plan as a strategy to decrease poor birth outcomes. J Obstet Gynecol Neonatal Nurs 2011; 40:109-19. doi: 10.1111/j.1552-6909. 2010.01203.x. 